\title{
Multi-agent knowledge integration mechanism using particle swarm optimization*
}

\author{
Kun Chang Lee ${ }^{1}$, Namho Lee ${ }^{2}$, Habin Lee ${ }^{3}$ \\ ${ }^{1}$ Professor at SKK Business School \\ WCU Professor at Department of Interaction Science \\ Sungkyunkwan University \\ Seoul 110-745, South Korea \\ kunchanglee@naver.com, leekc@skku.edu
}

${ }^{2}$ EMC Korea

Yeoksam 1-737, Kangnam-Ku

Seoul 135-984, Republic of Korea

${ }^{3}$ Brunel Business School

Brunel University

Uxbridge, Middlesex, UK

\footnotetext{
* This research was supported by the WCU (World Class University) program through the National Research Foundation
} of Korea funded by the Ministry of Education, Science and Technology (Grant No. R31-2008-000-10062-0). 


\title{
Multi-agent knowledge integration mechanism using particle swarm optimization
}

\begin{abstract}
:
Unstructured group decision-making is burdened with several central difficulties: unifying the knowledge of multiple experts in an unbiased manner and computational inefficiencies. In addition, a proper means of storing such unified knowledge for later use has not yet been established. Storage difficulties stem from of the integration of the logic underlying multiple experts' decisionmaking processes and the structured quantification of the impact of each opinion on the final product. To address these difficulties, this paper proposes a novel approach called the multiple agent-based knowledge integration mechanism (MAKIM), in which a fuzzy cognitive map (FCM) is used as a knowledge representation and storage vehicle. In this approach, we use particle swarm optimization (PSO) to adjust causal relationships and causality coefficients from the perspective of global optimization. Once an optimized FCM is constructed an agent based model (ABM) is applied to the inference of the FCM to solve real world problem. The final aggregate knowledge is stored in FCM form and is used to produce proper inference results for other target problems. To test the validity of our approach, we applied MAKIM to a real-world group decision-making problem, an IT project risk assessment, and found MAKIM to be statistically robust.
\end{abstract}

Keywords: Agent-based model (ABM), Particle swarm optimization (PSO), Fuzzy cognitive map (FCM), Expert knowledge, Knowledge integration, IT project risk assessment

\section{Introduction}

Most group decision-making problems are difficult to automate via information systems due to their strategic natures. Such problems include many subjective and qualitative variables stemming from a large number of decision-makers (Choudhury et al., 2006; Mintzberg et al., 1976). While many studies have explores techniques to support strategic group decision-making such as AHP (Satty, 2001) and DELPHI (Dalkey and Helmer, 1963), they fail to capture the subjective logic of the participants, which is used to judge the complex relationships between a number of variables. As a result, the knowledge created from past decision-making processes is lost and unavailable for use in future problems of a similar nature. The capture of this knowledge is extremely important in effective group decision-making.

In recent years this topic becomes a main focal point because more and more companies are aware that new ideas generated in past decision-making processes are a valuable source of information for the company. Thus, many new software applications appear that are successfully applied in medium to large companies for group decision making. Examples for these tools are Innovator of 
ARAS (http://www.ara.com), Innotour of University of Southern Denmark, EU, and Danish Ministry of Science, Technology and Innovation (http://www.innotour.com/), E.mind of Procter \& Gamble (http://www.procterandgamble.com/), Hype of Think 2 innovate (http://www.think2innovate.de), and HypelMT of Hype (http://www.hypeinnovation.com/).

Beside this, current literature in this field focus on agent and multi-agent based approaches (Ghanem et al, 2010; Wu et al. 2010), multi criteria decision analysis (Cunningham and Van der Leia 2009), text classification (Thorleuchter et al. 2010), database approaches (Geschka et al. 2002), Delphi studies (Prusty et al. 2010), cross impact analysis (Thorleuchter et al. 2010), and knowledge supply networks (Xiwei et al. 2010).

In contrast to previous work, this paper proposes a new method to integrate the knowledge of multiple experts, represent the knowledge in an explicit form, and employ it in strategic decisionmaking. We named this method the multiple agent-based knowledge integration mechanism (MAKIM). Its main processes are as follows.

First, a fuzzy cognitive map (FCM) is used to represent each expert's knowledge of a target problem. Second, a draft FCM representing the integrated knowledge base of the target problem is developed by roughly summing the knowledge of multiple experts. Third, the draft FCM is optimized by applying a particle swarm optimization (PSO) algorithm to the training data. Fourth, a final integrated knowledge base is derived when the PSO reaches an optimal state. The resulting knowledge base is stored in a final FCM, the validity of which is tested in the final step.

Section 2 provides a brief introduction on FCM, Agent-based Model, and PSO and their applications. Section 3 gives a schematic overview of the proposed MAKIM and section 4 the experiments used to test the method based on a real data set for project risk assessment. Section 5 discusses the implications of our results and suggests areas of future study.

\section{Background}

\subsection{Fuzzy Cognitive Maps}

Cognitive maps (Axelrod, 1976) and FCMs (Kosko, 1986) have emerged to represent the implicit knowledge of multiple people and can be used to link a multitude of scenarios. Cognitive maps and FCMs share common theoretical backgrounds, as they are both a collection of nodes linked by arcs or edges. Like a Bayesian network, an FCM is a useful tool to model and make inference on causal relationships among qualitative or quantitative concepts like global warming, profits, and 
competitiveness. Both Bayesian networks and FCMs use networks of concepts which are linked each other via directed arcs to represent the direction of influence, and they can represent and handle circular causality. However, Bayesian networks have a limitation to be applied to real world cases due to the difficulty of finding appropriate conditional probability models. Furthermore, it is difficult to represent vagueness on the relationships between concepts. Therefore, FCMs have been preferred to Bayesian networks for solving real world problems (Liu, 2003).

In an FCM, nodes represent concepts or variables relevant to a given problem domain, while arcs or edges represent the causal links between these nodes and are oriented to show the direction of influence between two nodes. Edges carry either a positive sign to signify a stimulating effect or a negative sign to signify an inhibitory effect. These maps are used to predict outcomes when decision-makers apply changes to several nodes of interest. The predicted outcomes are used to recommend strategic changes to nodes of interest. Predictions result in a set of node recommendations to be used as strategies in the real world.

Proposed by Kosko as an extension of cognitive maps (1986, 1992), a FCM possesses the following characteristics: (1) causal relationships between two nodes are defined as fuzzy numbers ranging from -1 to +1 (Lee et al., 1992; Lee and Lee, 2003) and (2) its inference reduces to a fixed state or equilibrium after a limited cycle of iterations using a fixed threshold (usually 0.5) (Kosko, 1992). Figure 1 depicts a typical FCM where the causality coefficients are between -1 and +1 .

\section{${ }^{* *}$ Insert Figure $1^{\text {** }}$}

Typical advantages of an FCM include (1) visual modeling of implicit knowledge about the target problem using nodes and edges with associated signs and causality coefficients, (2) uncertainty processing that improves decision-making quality, and (3) what-if/goal-seeking simulations and prediction capabilities. Although it is difficult to objectively quantify causality coefficients, FCMs allow a set of identified causality coefficients to be organized in an adjacency matrix for effective simulation.

FCMs are especially useful for solving unstructured problems involving many variables and their causal relationships. One example is in the field of administrative sciences, in which many decision variables and uncontrollable variables are causally interrelated (Eden \& Ackermann, 1989). FCMs have been used for geographical information systems (Liu \& Satur, 1999), the design of electronic commerce web sites (Lee \& Lee, 2003), R\&D project selection (Salmeron, 2009), knowledge management (Noh et al., 2000), bosphorus crossing problems (Ulengin et al. 2001), wayfinding processes (Chen \& Stanney,1999), decision analysis (Zhang et al., 1989), business process 
redesign (Kwahk \& Kim, 1999), business process analysis and reengineering (Xirogiannis and Glykas, 2004), complex war games (Klein \& Cooper,1982), strategic planning problems (Ramaprasad \& Poon, 1985), software operations support (Nelson et al., 2000), information retrieval (Johnson \& Briggs ,1994), decision support systems (Stylios et al., 2008; Mateou and Andreou, 2008), and distributed decision-process modeling (Zhang et al., 1994).

Similar to our research project, FCMs have been utilized to support group decisions. For example, Clarke et al. (2000) integrated individual cognitive maps of retail decision-makers into a unified map that represented a group knowledge base of the factors influencing retail performance. Khan and Quaddus (2004) used an FCM to solve a group decision-making problem by integrating individual FCMs into one unified map representing the group knowledge base. However, this paper is different from existing studies in that the latter is focused on aggregating individual expert knowledge via an FCM (rough summing) while the former employs ABS and PSO to enhance the FCM more precisely so that the predictability of the model is improved.

\subsection{Agent-Based Model and MAKIM}

An agent-based model ( $A B M)$ is used to integrate the knowledge of multiple experts into a single FCM. ABM is useful in modeling the complexities that underlie the interrelationships among a set of relevant variables with respect to the target problem. ABM simulation explicitly represents the dynamic nature of the interrelationships among the variables under consideration (Heckbert et al., 2010; Epstein, 2006). Therefore, ABMs have been used extensively to study social, economic, and organizational phenomena (Axelrod, 1997; Gilbert and Troitzsch, 1999; Ilgen and Hulin, 2000; Lomi and Larsen, 2001; Epstein 2006). ABM is a useful simulation to analyze complex stochastic patterns in the real world, particularly when the target problem is not solvable in an analytical fashion or when multiple possible equilibria exist (Ilgen and Hulin, 2000).

The basic elements of ABM include a set of agents referring to autonomous entities such as a person, firm, or other type of organization. Such autonomous entities are self-contained and can control their own actions based on their understanding of the operating environment (Woodridge and Jennings, 1995; Huhns and Singh, 1998). Agents can interact with each other through a predefined common language and/or protocol either to pursue their tasks more effectively or to respond proactively to changes in the environment (Gilbert and Troitzsch, 1999). Though a single agent carries little weight in the vast space of feasible solutions to the target problem, solutions form when a network of agents affects each other's behaviors by pursuing their own individual goals. Schelling (1978) expertly describes this phenomenon as a close relationship between micromotivation and macro-behavior (1978). The strength of ABM lies in its abilities to simulate the 
behaviors of individual agents, facilitate their interactions with each other and the environment, and foster emergent macro-level patterns of behavior (Schelling, 1978; Axtell, 2000). Such emergent macro-patterns are depicted as graphs or numbers that usually provide solutions to the target problem. By facilitating simple acts by individual agents, ABM models often yield unexpected outcomes and meaningful patterns that represent solutions with abundant strategic implications (Epstein and Axtell, 1996; Epstein, 2006).

ABM has several additional advantages. In particular, ABM-based model is relevant to our study of the inference of an FCM to accumulate inference process knowledge for improving the result explanation capability of MAKIM. More precisely, each concept node of an FCM is modeled as an agent which communicates with other agents (concept nodes) of the FCM for the inference. The agent based inference has advantage in that each agent can store interim results of inference processes and can make decision autonomously to reduce inference time. The detail of the proposed ABM-based inference is described in section 3.

\subsection{PSO and MAKIM}

\subsubsection{Overview of PSO}

We used PSO in our proposed MAKIM to integrate the knowledge of multiple experts in order to solve a poorly-structured target problem. Such a poorly-structured problem is usually difficult to solve if tackled as a whole. However, if the problem is tackled with a population of random candidate solutions conceptualized as particles, it can likely be solved in an evolutionary manner (Trelea, 2003). The basic concept of PSO begins with the directive "divide and conquer." In other words, the solution is sought by the repetitive iteration of combining a set of particles (or part-solutions) in a way that continually improves the solution. When an improved solution is no longer possible, the global solution of the target problem has been reached.

This iterative concept was initiated by Kennedy and Eberhart $(1995,2001)$ as a metaphor for social behavior. In the context of PSO, a final solution is reached by following these steps.

- Step 1: Initialize a population of random candidate solutions or particles.

- Step 2: Each particle is randomly assigned a velocity and is moved iteratively through the problem solution space.

- Step 3: Each particle is attracted towards the locations of best personal fitness and the best population fitness (global algorithm version).

- Step 4: If the new location can be further improved by another iteration, repeat Steps 2 and 3. 
Otherwise, stop.

As these steps illustrate, PSO solution search processes can be described as explorationexploitation tradeoffs. Exploitation refers to the further refinement of the current solution, while exploration refers to study of unexplored regions of the solution space. Although exploration requires more energy than exploitation in the form of costs and time, successful acts of exploration yield an improved solution. In contrast, if exploration fails to improve the current solution, valuable resources were wasted. The benefits of exploitation are clear: resources are not wasted when an improved solution is not attained. However, restricting the process to exploitation does not guarantee improved solutions. In this way, PSO involves a balance between exploration and exploitation.

We will explore a one-dimensional case to illustrate the basic PSO algorithm. At iteration $k$, the velocity $v_{k+1}$ is updated based on its current value according to a momentum factor a and on a term which attracts the particle towards the previously identified best position (or solution) $p_{1}$, as well as towards the best global position $p_{2}$. The strength of attraction is represented by the coefficients $b_{1}$ and $b_{2}$. The particle position $x_{k}$ is updated using its current value and the newly computed velocity $v_{k+1}$, which is affected by coefficients $c$ and $d$. In a one-dimensional case, $c$ and $d$ can be set to unity without loss of generality. Randomness-representing exploration acts are denoted by $r_{1}$ and $r_{2}$, which usually represent uniformly-distributed random numbers in the range $[0,1]$. In a onedimensional case, the PSO algorithm is stated symbolically as follows.

$$
\begin{aligned}
& v_{k+1}=a \cdot v_{k}+b_{1} \cdot r_{1} \cdot\left(p_{1}-x_{k}\right)+b_{2} \cdot r_{2} \cdot\left(p_{2}-x_{k}\right) \\
& x_{k+1}=c \cdot x_{k}+d \cdot v_{k+1}
\end{aligned}
$$

The one-dimensional case in equations 1 and 2 can be expanded to an $n$-dimensional case as shown below. All variables in equations 3 and 4 are n-dimensional vectors, and the symbol $\otimes$ represents element-by-element vector multiplication.

$$
\begin{aligned}
& \mathbf{v}_{k+1}=\mathbf{a} \otimes \mathbf{v}_{\mathbf{k}}+\mathbf{b}_{1} \otimes \mathbf{r}_{1} \otimes\left(\mathbf{p}_{1}-\mathbf{x}_{\mathrm{k}}\right)+\mathbf{b}_{2} \otimes \mathbf{r}_{2} \otimes\left(\mathbf{p}_{2}-\mathbf{x}_{\mathrm{k}}\right) \\
& \mathbf{x}_{\mathrm{k}+1}=\mathbf{c} \otimes \mathbf{x}_{\mathrm{k}}+\mathbf{d} \otimes \mathbf{v}_{\mathrm{k}+1}
\end{aligned}
$$

These detailed equations portray the basic concepts of PSO. These concepts can be metaphorically 
described by the natural rules followed by a school of fish or flock of birds that enable them to move together without collision and synchronize as if controlled by a central commander. Each animal moves based on its own simple rules of activity and goal. In this way, PSO typically represents either swarm or collective intelligence. All individuals in a swarm can synchronize and demonstrate emergent patterns of holistic behavior. Similarly, when PSO is applied to a target problem, a population of potential solutions is searched in an evolutionary way using a balance of exploration and exploitation.

The first step of PSO is to define the target problem as a combinatorial optimization problem (Parsopoulos and Vrahatis, 2002). Once the target problem is defined as a set of objective functions and constraints, problem solving using PSO logic is initiated. The worth of any PSO lies in determining proper weight matrices for the target problem through optimization of a properly defined objective function with constraints.

\subsubsection{Applying PSO}

MAKIM aims to determine an adjacency matrix that best represents the knowledge of multiple experts. We employed PSO to remain as rigorous as possible during this process.

\section{Preparation}

MAKIM begins with a preparation stage in which each expert's idea of the concept nodes is defined and used to represent the target problem and the causality coefficients of each edge between nodes. We employed an open interview technique for this stage (Rossi et al., 1983), in which we asked the experts about the characteristics of and factors relating to the target problem (Nelson et al., 2000). For instance, the interviewer may ask, "What characteristics or factors come to your mind when you hear 'project risk'?" Their answers helped to define an appropriate number of concept nodes and related causality coefficients. Next, we established consensus among experts with regard to the attributes (or concept nodes) extracted from the interviews. In this step, each expert viewed the complete list of attributes gathered from the interview and selected the concept nodes with which they agree. We then surveyed experts regarding the relationships between all concepts extracted in the previous step and asked them to draw arrows between the concepts and to designate each as a positive or negative relationship. These causal relationships were then quantified. In other words, the semantic expression 'A has a positive effect on B' was expressed as a value from $r_{a b}[0,1]$. Similarly, 'C has a negative effect on D' was expressed as a value from $r_{c d}[-1,0]$. The quantified causality coefficient $[\alpha, \beta]$ indicates a causality value greater than or equal to $\alpha$ and less than or equal to $\beta$. When all causal relationships were quantified with proper causality values by an 
individual expert $i$, his or her knowledge was defined as an adjacent matrix $E_{i}$ :

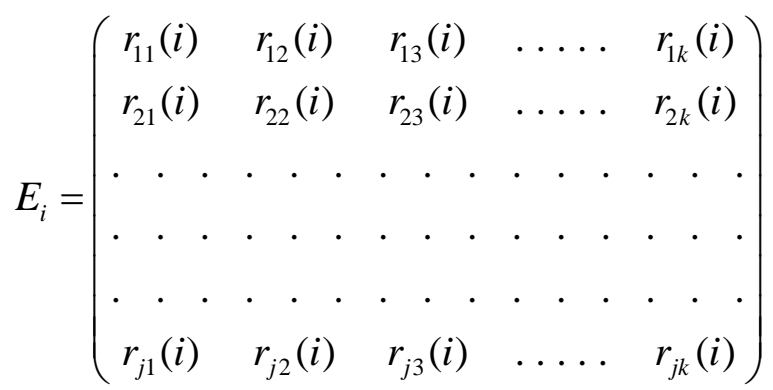

where $j=k=$ the number of concept node in the FCM.

Therefore, the mathematically integrated knowledge of $n$ experts can be developed by aggregating $n$ expert adjacency matrices. If the aggregated adjacency matrix is denoted by $E_{T}$, then it is expressed as

$$
E_{T}=\sum_{i=1}^{n} E_{i}
$$

The operation ' + ' between the relation matrix of different experts is defined as follows:

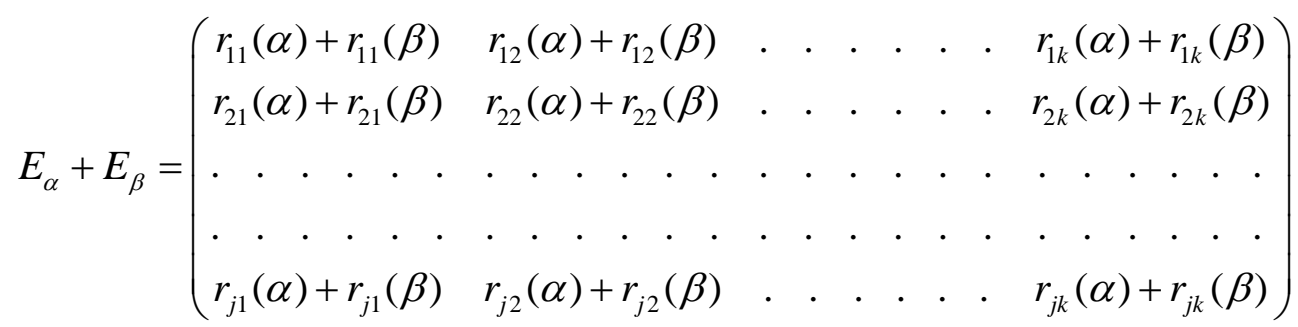

Where the '+ ' operation between the quantified relation $r_{i}$ and $r_{j}$ is defined as follows:

$r_{i}=\left[\alpha_{1}, \beta_{1}\right], r_{j}=\left[\alpha_{j}, \beta_{j}\right]$

$r_{i}+r_{j}=\left[\right.$ small value between $\alpha_{i}$ and $\alpha_{j}$, large value between $\beta_{i}$ and $\left.\beta_{j}\right]$

Because of this '+' operation, if there is differece between experts' knowledge on the causal relations, then the quantified relationship range increases. That is, the uncertainty of the causal relation values increases.

\section{Objective Function and Constraints}

MAKIM produces final aggregate knowledge (i.e., mathematically integrated knowledge) $E_{T}$ by applying PSO to the objective function and constraints according to the training data which is obtained from experts. For the training data, experts are asked to enter values for an output node 
for different combinations of input node values.

Assume a $D$-dimensional search space $S$ and a swarm of $n$ particles or experts. The $i$-th particle $\left(E_{i}\right)$ is a possible relation in $E_{T}$, which is the total set of possible relations. The PSO algorithm described in section 2.3.1 is applied using below objective function.

$\operatorname{Min} . \sum_{i=1}^{n} e_{i}, \quad e_{i}=\sqrt{\left(A_{i-o u t}-\bar{A}_{i-o u t}\right)^{2}}$

where

$$
\begin{aligned}
& A_{i-\text { out }}=C_{i} \times E_{i} \\
& \bar{A}_{i-\text { out }}=\text { Average }\left[A_{1 i}, A_{2 i}, \ldots, A_{k i}\right] \\
& C_{i}=\left[C_{1 i}, C_{2 i}, \ldots, C_{k i}\right]
\end{aligned}
$$

where $\mathrm{k}$ is the total number of concept nodes in the Adjacency matrix.

The objective function is to minimize the summation of errors of each particle $\left(e_{i}\right)$ between the training data value (the average output node value estimated by the expert $i$, Eq. 5) and the calculated inference value (Eq. 6). Therefore, the objective function determines $E_{T}$, the optimally aggregated knowledge of $n$ experts. That is, the objective function is used to calculate the best position of each particle $\left(p_{1}\right)$ and best global position $\left(p_{2}\right)$ in Eq. 1). From the perspective of PSO, $E_{T}$ is the optimal adjacency matrix that satisfies the given training data.

\section{Methodology}

In the previous section, we discussed two major mechanisms used in MAKIM: ABM and PSO. We now consider how our proposed MAKIM can be used to extract a reliable and robust knowledge base from multiple experts when applied to a complex problem domain.

\subsection{MAKIM Steps}

MAKIM can be summarized in four steps: (1) determination of nodes and causal relationships (draft FCM), (2) determination of fuzzy values for input nodes, (3) preparation of training data, and (4) application of ABM and PSO to the draft FCM and training data set to calculate the final causal relationships and causality coefficients. To assess the validity of MAKIM, we applied it to an IT project risk assessment. System integration companies must predict IT project risk before submitting proposals and entering the bidding stage. Proposals are usually reviewed by a risk 
manager with experience as the project manager (PM) of many IT projects. The risk manager comments on the project's risk factors based on a bidding document that includes financial information, a resource plan, the contract type, client status, and the proposed solution. Subsequently, the bid manager, who becomes the PM when the bid is won, adjusts bidding strategies according to the recommendations of the risk manager. Prediction of the project's potential risks is difficult, as much of the knowledge held by the risk manager is tacit and based on experience. For this reason, it is highly important to devise a more reliable and objective mechanism of risk assessment.

\section{Step 1: Determination of nodes and causal relationships}

To organize a draft FCM, we interviewed ten experts each with over a decade of experience as an IT PM. After two rounds of interviews, 24 concept nodes were selected as factors deemed to affect project risk. We categorized these concept nodes as input or output nodes, where input nodes were those specified before beginning the project and output nodes were those subsequently computed. Based on the interview data, we then determined the draft causal relationships between the 24 concept nodes. Table 1 shows 24 concept nodes and draft relationships among them.

\section{** Insert Table 1 **}

\section{Step 2: Determination of fuzzy values for input nodes}

As described in Table 1, concept nodes must be used with caution in actual risk assessment. The possible values of these nodes should be fuzzified to trigger the FCM, which is the core of MAKIM. Fuzzy values were determined by interviewing a focus group composed of five additional PMs. Table 2 summarizes the fuzzy values for each concept node.

\section{** Insert Table 2 **}

\section{Step 3: Preparation of the training data}

We used the training data set to refine the draft FCM using PSO. For training purposes, ten training samples were collected and their risks were evaluated by experts. Table 3 summarizes the training data which were used during PSO to refine draft causal relationships and their related causality coefficients.

$$
\text { ** Insert Table } 3 \text { ** }
$$

Step 4: Application of PSO to the training data set in order to produce a final FCM PSO was applied to the draft FCM and training data to determine an appropriate knowledge base in 
FCM form. In this way, the knowledge of ten experts regarding project risk assessment were integrated seamlessly, as is described in step one. PSO worked to identify a set of causal relationships and optimal causality coefficients by reducing errors over 1243 iterations. The minimum error in this study was 0.645 . Figure 2 depicts the error curve and a MAKIM snapshot. The aggregate knowledge represented in an FCM is extracted by PSO using the training data set (refer to Figure 3)

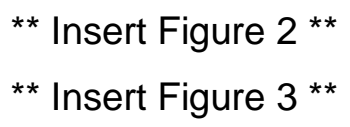

\section{Step 5: Application of ABM to solve target problem}

In the last step, we applied ABM to the inference of the FCM constructed in the previous step to solve problems. A fuzzy conversion table developed in the step 3 was used in this step. Inference based on FCM is a key functionality to provide end users with a solution for a given problem. A traditional FCM inference algorithm is limited for explaining inference results. Providing explanations for recommended actions is considered one of the most important capabilities of expert systems. In this paper, a multi-agent-based causal map inference algorithm, which can explain the inference process, was developed for knowledge inference by using an FCM. The main concept is that each node in the FCM is represented by an intelligent agent who, depending on the situation, can change the direction of its connected arcs and weight on the arcs autonomously. This can overcome the drawbacks of traditional FCMs with regard to recording the inference process knowledge for later use for explanation functionality. Furthermore, the time concept can be addressed in the inference process. Agents recognize time automatically and timely react to the actions of related neighbor agents or other changes. Let us assume a simple FCM example that has only four nodes A, B, C, and D with $W_{i}\left(T_{i}\right)=$ Weight (Time Lag) in Figure 4. The weight on the arc between A and D can vary between 0.2 and 0.8 . The life of this FCM model consists of periods because there are time lags between node $A$ and $C$ and between $C$ and $D$. 'A $\rightarrow C \rightarrow D$ ' is the longest time path.

\section{** Figure 4 **}

In the proposed inference algorithm, each change in the node values is defined as a new event. Every event has a time value. The events are processed at specific time. In this example, at the time period zero (Time $=0)$, the initial node values of $A(0.5), B(0.6)$ are considered given events by the coordination agent. The coordination agent checks the time to determine if the events should be processed in the time period. Table 4 shows the calculation steps for each node at each time period. The time lag between $B$ and $C$ is 0 , so the node agent ' $C$ ' reacts to the event ' $B=0.6$ ' at time period 0 . Node ' $D$ ' is not affected by any event at time period 0 , and Node ' $D$ ' therefore does not have any value at time period 0 . At time period 1 , Node ' $C$ ' is affected by the event ' $A=0.5$ '. 
Therefore, the value of node ' $C$ ' at time period 1 becomes $f\left(0.5^{*} 0.8\right)$. ' $f(x)$ ' is an inference function, and 0.8 is the weight on the arc between $A$ and $C$. At the same time node ' $D$ ' is affected by the event ' $A=0.5$ ' and the event generated from node ' $C$ ' $(B \rightarrow C \rightarrow D)$ simultaneously. When the event goes through the arc between 'A' and 'C', Node agent ' $D$ ' selects a weight value between 0.2 and 0.8 . At time period 2 , there is only one event given to node ' $D$ ' $(A \rightarrow C \rightarrow D)$.

** Table 4 **

\section{Summary of the proposed Algorithm}

Step 1: Check initial input.

Step 2: Generate initial event.

Step 3: Each node agent collects the event sent to them and records the event processing history.

Step 4: Generate new event.

Step 5: If there are no more events to be generated, then stop. Otherwise, go to Step 3.

Step 6: Time $=$ Time +1 .

Step 7: If Time > the longest time path in the FCM and no more events exist, then stop. Otherwise, go to Step 1.

In the inference algorithm, all event-processing histories are recorded as described in step 3 of the algorithm. An event has following structure: , evt $t_{i}$ (target node, value) where $i$ is event index. This provides users with an explanation of the inference output through an analysis of the records.

\section{Experiment and Discussion}

We used a test data set comprised of 32 items to validate MAKIM. We applied the aggregate FCM knowledge to the test data set and obtained results as summarized in Table 5. Testing yielded a risk assessment accuracy rate of $94 \%$, impressively high compared to practical accuracy rates (50-60\%). Testing showed that MAKIM can provide a robust knowledge base derived from multiple experts, and that the aggregate knowledge can easily be applied to real-world problems.

\section{** Insert Table 5 **}

The major contributions of MAKIM to this field of research are its ability to (1) synthesize the knowledge of multiple experts using ABM and PSO, (2) produce objective aggregate knowledge, (3) store the knowledge in FCMs for use in similar future problems, and (4) provide robust inference capability to solve the target problem via an agent based inference. Implications of MAKIM are therefore as follows. 
First, MAKIM illustrates the use of FCM methodology powered by both ABM and PSO to synthesize the knowledge of multiple experts in a specific problem domain. The method can provide robust decision support for poorly-structured problems such as IT project risk assessment, where multiple experts must cooperate to produce a unified solution.

Second, from an academic perspective, MAKIM can effectively support a group decision-making process by integrating ABM and PSO, and applying to FCM. MAKIM's contribution like this is unique, which can be compared with some studies in literature. For example, Carlsson and Walden (1996) used a cognitive map to develop a system to support strategic management decisions at the individual, group, and corporate levels. Several years later, Clarke et al. (2000) showed how individual cognitive maps of retail decision makers can be unified to represent group knowledge about the factors that influence retail performance. Furthermore, Khan and Quaddus (2004) applied FCM to a group decision-making problem by integrating individual decision-maker FCMs into a unified FCM that represented their aggregate knowledge. Rodriguez-Repiso et al. (2007) also proposed FCM methodology to model IT project success. However, their contribution was focused on modeling the relationships between success factors, leaving the FCM-based learning algorithm for future study. Most recently, Bueno and Salmeron (2009) compared FCM activation functions for a group decision-making problem similar to the project risk assessment presented in this paper. As is discussed so far, previous studies lack the rigor that MAKIM provides.

\section{Concluding Remarks}

As real-world problems increase in sophistication and market competition becomes fierce, the need has emerged for effective decision support to solve poorly-structured problems. This need is especially pertinent when the target problem requires the coordination of knowledge between experts. Until now, no successful mechanisms have been developed to produce aggregate knowledge based on multiple experts to solve a target problem. In MAKIM, ABM and PSO are used to produce a unified FCM as an aggregate knowledge base to solve the target problem.

The major contributions of the proposed mechanism are as follows. First, experts are usually adamant about their position on a target problem. In problems with high stakes, the group must reach agreement despite the difficulties inherent in synthesizing their positions. An objective mechanism for knowledge integration is useful to resolve disagreements and offers computational efficiency. We found this proposed MAKIM to be both effective and stable in solving such tasks. Second, the synthesis of ABM and PSO was incredibly helpful to integrate the knowledge of multiple experts. ABM provides a platform in which a set of concept nodes and causal relationships are represented by agents. Multiple agents work together to produce the most reliable and robust FCM for the given target problem. PSO supplies a computing powerhouse through which complicated causality coefficients can be computed from the training data set. 
There still remain areas of future research. We believe that MAKIM could be incorporated into an ABM-based expert system as the knowledge base as well as the inference engine. If such a system is successfully developed, it can be applied extensively to a range of decision-making problems. Finally, we suggest that a combination of ABM and PSO be applied to other types of problems to develop novel and useful solutions.

\section{References}

R. Axelrod, Structure of Decision - The Cognitive Maps of Political Elites, Princeton University Press, 1976.

R. Axelrod, The Complexity of Cooperation: Agent-Based Models of Competition and Collaboration, Princeton University Press, 1997.

R. Axtell, Why agents? On the varied motivations for agent computing in the social sciences, Center on Social and Economic Dynamics, The Brookings Institution, Working Paper 17 (2000).

J.L. Chen, K.M. Stanney, A theoretical model of way finding in virtual environments: proposed strategies for navigational aiding, Presence 8 (6) (1999) 671685.

A.K. Choudhury, R. Shankar, M.K. Tiwari, Consensus-based intelligent group decision-making model for the selection of advanced technology, Decision Support Systems 42 (3) (2006) 1776 1799.

I. Clarke, M. Horita, W. Mackaness, The spatial knowledge of retail decision makers: capturing and interpreting group insight using a composite cognitive map, International Review of Retail, Distribution and Consumer Research 10 (3) (2000) 265285.

M. Clerc, The swarm and the queen: towards a deterministic and adaptive particle swarm optimization, Proceedings of ICEC, Washington DC (1999) 19511957.

M. Clerc, J. Kennedy, The article swarm-explosion, stability, and convergence in a multidimensional complex space, IEEE Transactions on Evolutionary Computation 6 (1) (2002) 5873.

S.W. Cunningham, T.E. Van der Leia, Decision-making for new technology: A multi-actor, multiobjective method", Technological Forecasting and Social Change 76 (1) (2009) 2638.

N. Dalkey, O. Helmer, An experimental application of the Delphi method to the use of experts, Management Science 9 (3) (1963) 458467.

R.C. Eberhart, Y. Shi, Comparing inertia weights and constriction factors in particle swarm optimization, Proceedings of the Congress on Evolutionary Computation, La Jolla, CA, USA (2000) 8488.

C. Eden, F. Ackermann, Strategic Options Development and Analysis (SODA) - Using a Computer to Help with the Management of Strategic Vision, in G. Miller, (ed.), Knowledge-Based Management Support Systems, UK: Ellis Horwood, (1989) 198207.

J.M. Epstein, Generative Social Science: Studies in Agent-Based Computational Modeling, Princeton University Press, 2006.

J.M. Epstein, R. Axtell, Growing Artificial Societies: Social Science from the Bottom Up. Boston: The MIT Press, 1996.

H. Geschka, T. Lenk, J. Vietor, The idea and project database of WELLA AG, International Journal of Technology Management 23 (5) (2002) 410416.

A.G. Ghanem, A.A. Minai, J.G. Uber, A multi-agent model for the co-evolution of ideas and communities, IEEE Congress on Evolutionary Computation (CEC), Barcelona, Spain, (2010) 1 8.

N. Gilbert, K.G. Troitzsch, Simulation for the Social Scientist. Buckingham: Open University Press, 1999.

S. Heckbert T. Baynes A. Reeson, Agent-Based Modeling in Ecological Economics, Annals of The New York Academy of Sciences 1185 (2010) 3953.

M.N. Huhns, M.P. Singh, Readings in Agents. San Francisco, CA: Morgan Kaufmann, 1998.

D.R. Ilgen, C.L. Hulin, (eds), Computational Modeling of Behavior in Organizations: The Third Scientific Discipline. Washington, DC: American Psychological Association, 2000. 
R.J. Johnson, R.O. Briggs, A model of cognitive information retrieval for ill-structured managerial problems and its benefits for knowledge acquisition, in: R.H. Sprague, Jr. (ed.), Proceedings of the Twenty-Seventh Hawaii International Conference on System Sciences, Los Alamitos, CA, USA, (1994) 191200.

J. Kennedy, R. Eberhart, Particle swarm optimization, in: Proceedings of IEEE International Conference on Neural Networks (ICNN'95), Perth, Australia, (1995) 19421948.

J. Kennedy, R. Eberhart, Y. Shi, Swarm Intelligence, Morgan Kaufmann Publishers, San Francisco, CA, 2001.

M.S. Khan, M. Quaddus, Group Decision Support Using Fuzzy Cognitive Maps for Causal Reasoning, Group Decision and Negotiation 13 (2004) 463480.

J.H. Klein, and D.F. Cooper, Cognitive maps of decision-makers in a complex game, Journal of the Operational Research Society 33 (1) (1982) 6371.

B. Kosko, Fuzzy Cognitive Maps, International Journal of Man-Machine Studies 24 (1986) 6575.

B. Kosko, Neural Networks and Fuzzy Systems, Prentice-Hall, New Jersey, 1992.

K.Y. Kwahk, Y.G. Kim, Supporting business process redesign using cognitive maps, Decision Support Systems 25 (2) (1999) 155178.

K.C. Lee, and S. Lee, A cognitive map simulation approach to adjusting the design factors of the electronic commerce Web sites. Expert Systems with Applications 24 (1) (2003) 111.

S. Lee, J.F. Jr. Courtney, R.M. O'Keefe, A system for organizational learning using cognitive maps, Omega 20 (1) (1992) 2336.

H.A. Linstone, M. Turoff, Delphi: A brief look backward and forward, Technological Forecasting and Social Change, In Press, 2010.

Z.Q. Liu, Fuzzy cognitive maps in GIS data analysis, Software Computing 7 (2003) $394-401$.

Z.Q. Liu, R. Satur, Contextual fuzzy cognitive map for decision support in geographic information systems, IEEE Transactions on Fuzzy Systems 7 (5) (1999) 495507.

A. Lomi, E.R. Larsen (eds), Dynamics of Organizations: Computational Modeling and Organization Theories, Menlo Park, CA: AAAI Press, 2001.

N.H. Mateou, A.S. Andreou, A framework for developing intelligent decision support systems using evolutionary fuzzy cognitive maps, Journal of Intelligent and Fuzzy Systems 19(2) (2008) 151 170.

H. Mintzberg, D. Raisinghani, A. Theoret, The structure of 'Unstructured' decision processes, Administrative Science Quarterly 21 (2) (1976) 246275.

S. Mittal, C. Dym, Knowledge Acquisition From mMultiple Experts, Al Magazine Summer (1985) 3.

K.M. Nelson, S. Nadkarni, V.K. Narayanan, M. Ghods, Understanding software operations support expertise: A revealed causal mapping approach, MIS Quarterly 24 (3) (2000) 475.

J.B. Noh, K.C. Lee, J.K. Kim, J.K. Lee, S.H. Kim, A case-based reasoning approach to cognitive map-driven tacit knowledge management, Expert Systems with Applications 19 (4) (2000) 249 259.

K.E. Parsopoulos, M.N. Vrahatis, Recent Approaches to Global Optimization Problems Through Particle Swarm Optimization, Natural Computing 1, Kluwer Academic Publishers, The Netherlands (2002) 235306.

S.K. Prusty, P.K.J. Mohapatra, C.K. Mukherjee, GOS tree (Goal-Objective-Strategy tree) approach to strategic planning using a fuzzy-Delphi process: An application to the Indian Shrimp Industry, Technological Forecasting and Social Change 77 (3) (2010) 442456.

A. Ramaprasad, E. Poon, A computerized interactive technique for mapping influence diagrams (MIND), Strategic Management Journal 6 (4) (1985) 377392.

J.L. Salmeron, Supporting decision makers with Fuzzy Cognitive Maps, Research-Technology Management 52(3) (2009) 5359

T.L. Saaty, Fundamentals of Decision Making and Priority Theory, Pittsburgh, Pennsylvania: RWS Publications, ISBN 0-9620317-6-3, 2001.

T.C. Schelling, Micromotives and Macrobehavior. New York: Norton, 1978.

B. Srdjevic, Linking analytic hierarchy process and social choice methods to support group decision making in water management, Decision Support Systems 42 (4) (2007) 22612273.

C.D. Stylos, V.V. Georgopoulos, G.A. Malandraki, ands. Chouliara, Fuzzy cognitive map architectures for medical decision support systems, Applied Soft Computing 8(3) (2008) 1243 
1251.

D. Thorleuchter, D. Van den Poel, A. Prinzie, Mining Ideas from Textual Information, Expert Systems with Applications 37 (10) (2010) 71827188.

D. Thorleuchter, D. Van den Poel, D., A. Prinzie, A compared R\&D-based and patent-based cross impact analysis for identifying relationships between technologies", Technological Forecasting and Social Change 77 (7) (2010) 10371050.

I.C. Trelea, The particle swarm optimization algorithm: convergence analysis and parameter selection, Information Processing Letters. 85 (2003) 317325.

F. Ulengin, Y.I. Topcu, and S.O. Sahin, An integrated decision aid system for Bosphorus watercrossing problem, European Journal of Operational Research 134 (1) (2001) 179192.

M. Woodridge, N.R. Jennings, Intelligent agents: theory and practice, Knowledge Engineering Review 10 (1995) 115152.

D.D. Wu, X. Kefan, L. Hua, Z. Shi, D.L. Olson, Modeling technological innovation risks of an entrepreneurial team using system dynamics: An agent-based perspective, Technological Forecasting and Social Change 77 (6) (2010) 857869.

G. Xirogiannis, M. Glykas, Fuzzy cognitive maps in business analysis and performance-driven change, IEEE Transactions on Engineering Management 51(3) (2004) 334351.

W. Xiwei, M. Stösslein, W. Kan, Designing knowledge chain networks in China - A proposal for a risk management system using linguistic decision making, Technological Forecasting and Social Change 77 (6) (2010) 902915.

W.R. Zhang, S.S. Chen, J.C. Bezdek, Pool2: a generic system for cognitive map development and decision analysis, IEEE Transactions on Systems, Man and Cybernetics 19 (1) (1989) 3139.

W.R. Zhang, W. Wang, R.S. King, A-Pool: an agent-oriented open system shell for distributed decision process modeling, Journal of Organizational Computing 4 (2) (1994) 127154. 


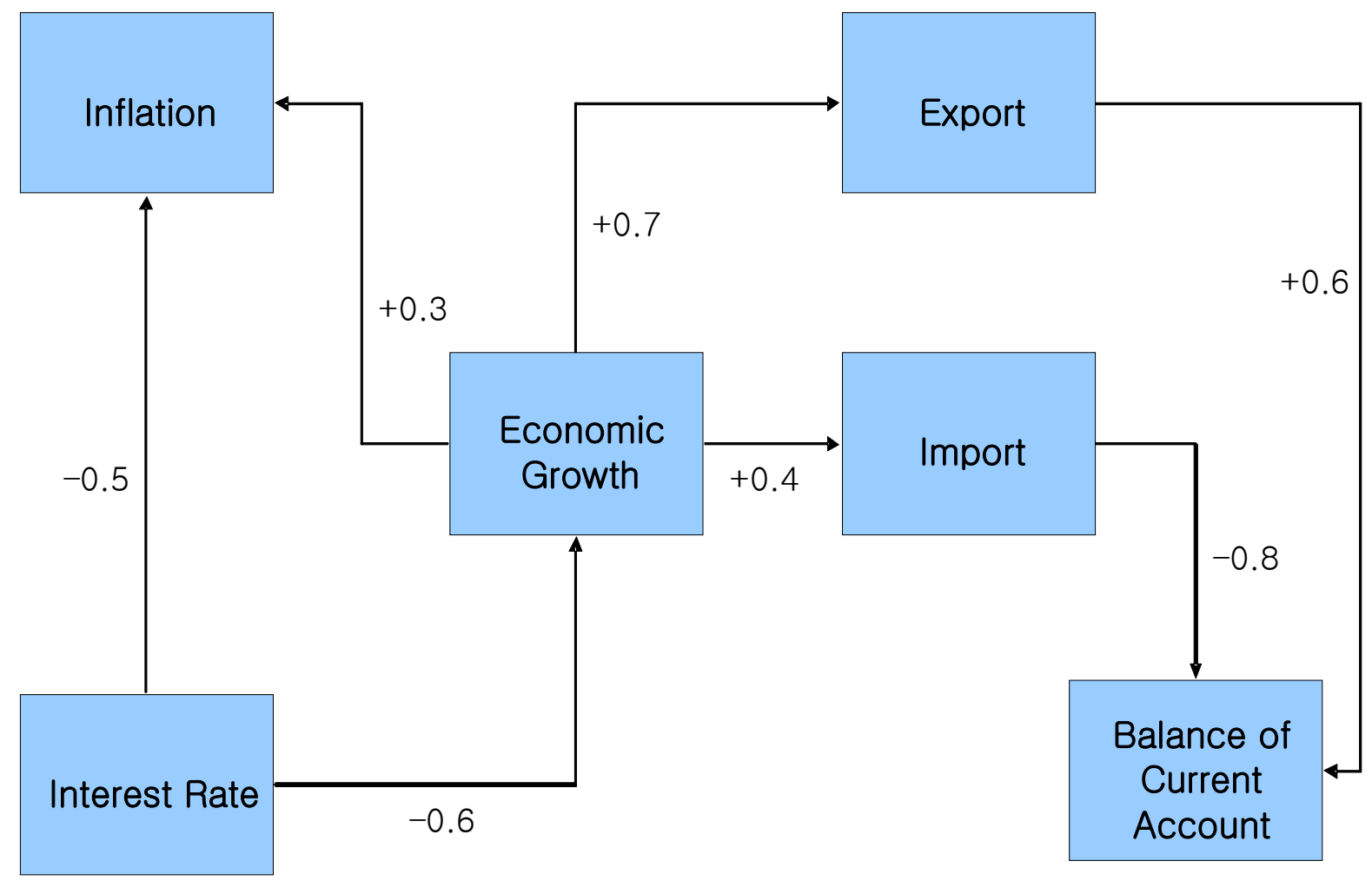

Figure 1. Fuzzy Cognitive Map 


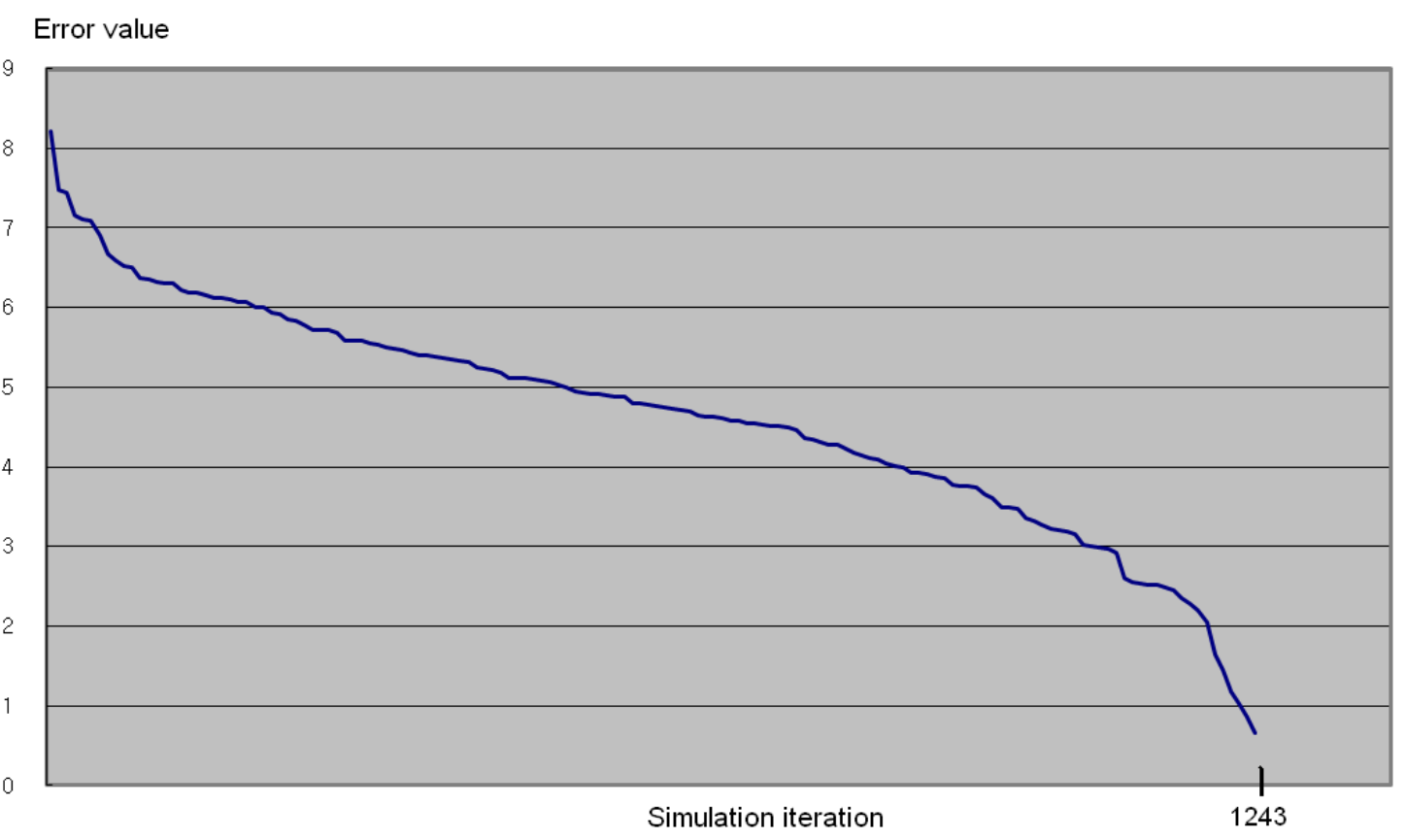

(a) Error curve of PSO with training data set
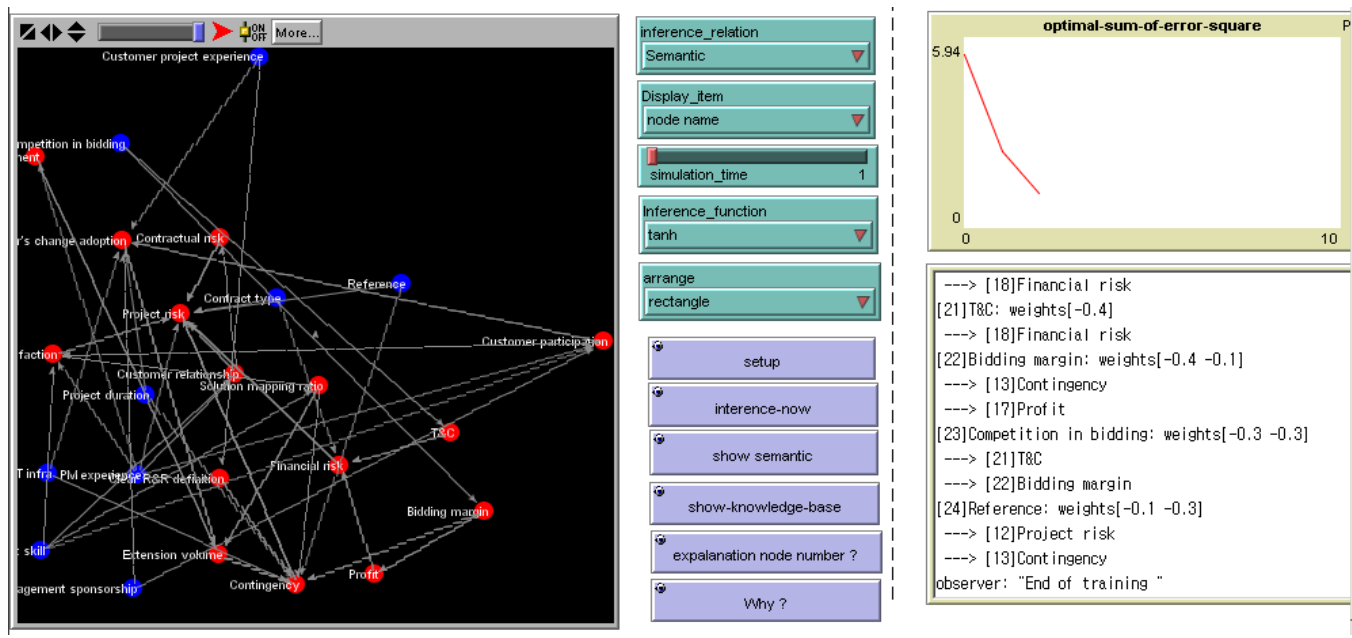

(b) User interface of MAKIM

Figure 2. MAKIM-based PSO simulation to obtain a final FCM 


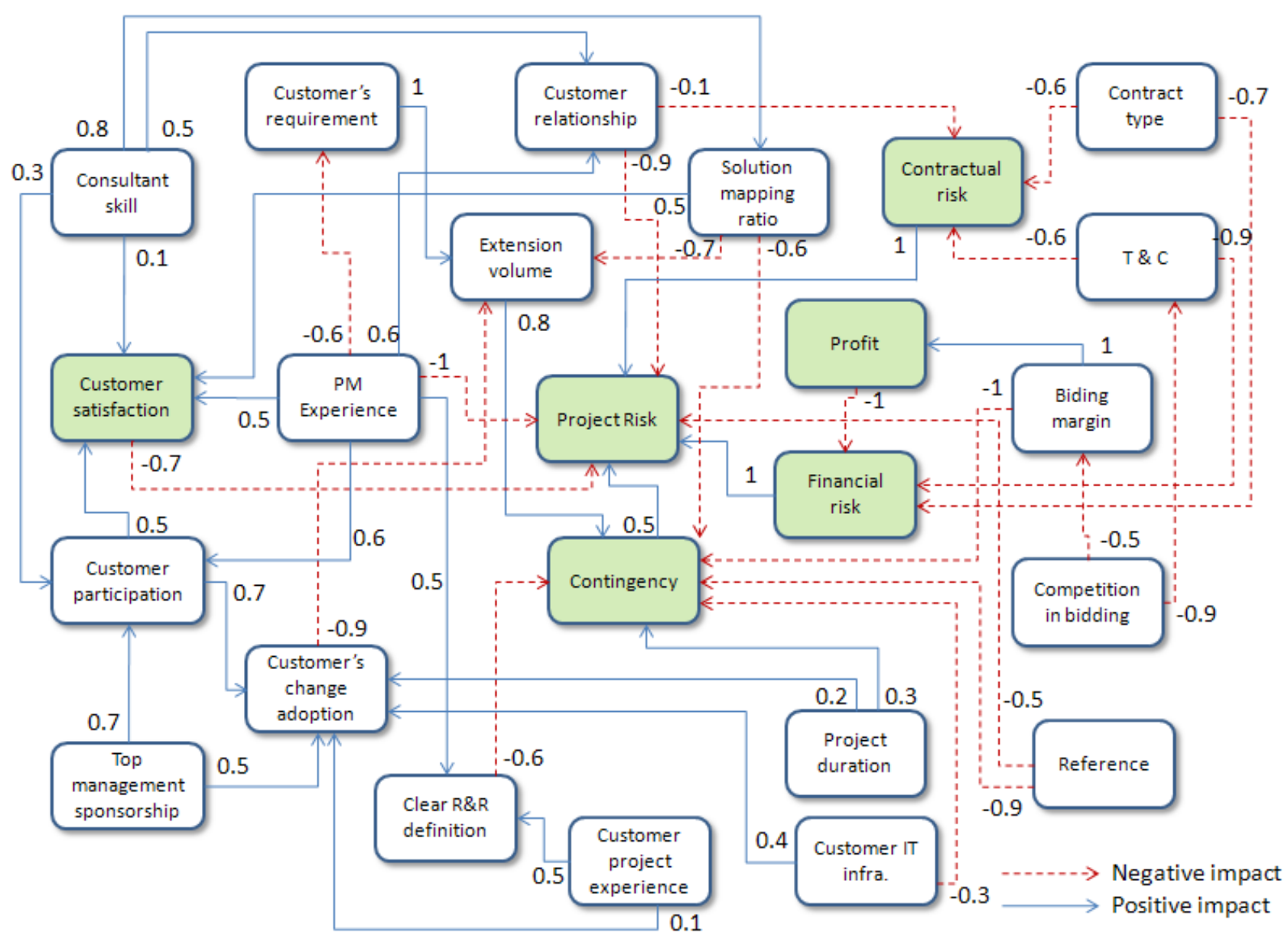

Figure 3. Final knowledge is presented in FCM form as suggested by MAKIM 


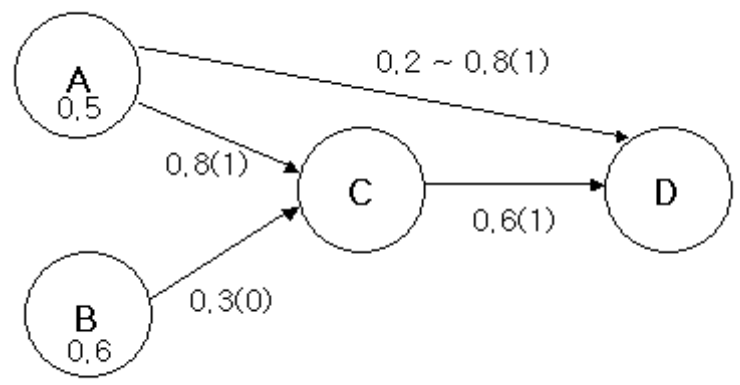

Figure 4. An example FCM 


\begin{tabular}{|c|c|c|c|}
\hline Number & Concept Node & Description & Input / Output \\
\hline 1 & Consultant Skill & Average experience of consultants & Input \\
\hline 2 & Customer IT Infra & $\mathrm{H} / \mathrm{W}, \mathrm{N} / \mathrm{W}, \mathrm{S} / \mathrm{W}, \mathrm{IT}$ training & Input \\
\hline 3 & Customer Satisfaction & Customer satisfaction with the project & Output \\
\hline 4 & Customer Participation & Customer involvement in the project & Input \\
\hline 5 & Top Management Sponsorship & Top management support for the project & Input \\
\hline 6 & PM Experience & Project Manager's experience & Input \\
\hline 7 & Customer Change Adoption & $\begin{array}{l}\begin{array}{l}\text { Customer's flexibility to } \\
\text { changes }\end{array} \\
\text { chant proposed }\end{array}$ & Input \\
\hline 8 & Customer Requirements & Additional customer requirements & Input \\
\hline 9 & Extension Volume & Expected extension or customization volume & Input \\
\hline 10 & Clear R\&R Definition & Level of clarity of roles and responsibilities & Input \\
\hline 11 & Customer Relationship & Historical relationship with this client & Input \\
\hline 12 & Project Risk & Anticipated project risk & Output \\
\hline 13 & Contingency & Contingency for this project & Output \\
\hline 14 & Solution Mapping Ratio & $\begin{array}{l}\text { Functional mapping ratio between } \mathrm{S} / \mathrm{W} \text { and } \\
\text { requirements }\end{array}$ & Input \\
\hline 15 & Customer Project Experience & Customer experience with IT projects & Input \\
\hline 16 & Contractual Risk & $\begin{array}{l}\text { Contractual risk that could result in legal } \\
\text { problems }\end{array}$ & Input \\
\hline 17 & Profit & Total profit margin of the project & Output \\
\hline 18 & Financial Risk & $\begin{array}{l}\text { Financial risks including revenue recognition } \\
\text { and collection problems }\end{array}$ & Input \\
\hline 19 & Project Duration & Total project duration & Input \\
\hline 20 & Contract Type & Time \& Material or Fixed Price & Input \\
\hline 21 & Terms \& Conditions & Favorable attributes of T\&Cs & Input \\
\hline 22 & Bidding Margin & Calculated bidding margin & Input \\
\hline 23 & Competition in Bidding & Number of competitors involved in the deal & Input \\
\hline 24 & Reference & Reference sites for similar projects & Input \\
\hline
\end{tabular}

(a) Draft concept nodes

1 gives positive effect on 3

1 gives positive effect on 4

1 gives positive effect on 11

1 gives positive effect on 14

2 gives positive effect on 7

2 gives negative effect on 13

3 gives negative effect on 12

4 gives positive effect on 3

4 gives small positive effect on 7

5 gives positive effect on 4

5 gives small positive effect on 7

6 gives positive effect on 3

6 gives positive effect on 4

6 gives negative effect on 8

6 gives positive effect on 10

6 gives positive effect on 11

6 gives negative effect on 12

7 gives small negative effect on 9

8 gives positive effect on 9

9 gives positive effect on 13

10 gives negative effect on 13

11 gives small negative effect on 12

11 gives small negative effect on 16

13 gives positive effect on 12

14 gives positive effect on 3

14 gives negative effect on 9

14 gives small negative effect on 13
15 gives small positive effect on 7

15 gives small positive effect on 10

16 gives small positive effect on 12

17 gives negative effect on 18

18 gives positive effect on 12

19 gives small positive effect on 7

19 gives small positive effect on 13

20 gives small negative effect on 12

20 gives small negative effect on 18

21 gives negative effect on 18

22 gives negative effect on 13

22 gives positive effect on 17

23 gives small negative effect on 21

23 gives negative effect on 22

24 gives negative effect on 12

24 gives negative effect on 13

(b) Draft causal relationships between concept nodes

Table 1. Concept nodes and causal relationships 


\begin{tabular}{|c|c|c|c|}
\hline Number & Concept Node & Actual Value & Fuzzy Value \\
\hline 1 & Consultant Skill & $\begin{array}{l}\text { Average level } 6 \\
\text { Average level } 5 \\
\text { Average level } 4 \\
\end{array}$ & $\begin{array}{r}1 \\
0.5 \\
0 \\
\end{array}$ \\
\hline 2 & Customer IT Infra & $\begin{array}{l}\text { Excellent } \\
\text { Average } \\
\text { Needs improvement }\end{array}$ & $\begin{array}{r}1 \\
0.5 \\
0\end{array}$ \\
\hline 3 & Customer Satisfaction & $\begin{array}{l}\text { Very satisfied } \\
\text { Satisfied } \\
\text { No complaints } \\
\text { Not satisfied } \\
\text { Many complaints }\end{array}$ & $\begin{array}{r}1 \\
0.5 \\
0 \\
-0.5 \\
-1\end{array}$ \\
\hline 4 & Customer Participation & $\begin{array}{l}\text { Aggressive } \\
\text { Average } \\
\text { Passive }\end{array}$ & $\begin{array}{r}1 \\
0 \\
-1\end{array}$ \\
\hline 5 & $\begin{array}{l}\text { Top Management } \\
\text { Sponsorship }\end{array}$ & $\begin{array}{l}\text { High interest in project } \\
\text { Moderate interest in project } \\
\text { Little interest in project } \\
\text { No top manaqement involvement }\end{array}$ & $\begin{array}{r}1 \\
0.7 \\
0.4 \\
0\end{array}$ \\
\hline 6 & PM Experience & $\begin{array}{l}\geq 12 \text { years } \\
7-11 \text { years } \\
5-6 \text { years } \\
\text { Less than } 5 \text { vears }\end{array}$ & $\begin{array}{l}1 \\
0.7 \\
0.4 \\
0.1\end{array}$ \\
\hline 7 & $\begin{array}{l}\text { Customer's Willingness } \\
\text { to Adopt Change }\end{array}$ & $\begin{array}{l}\text { Highly flexible } \\
\text { Moderately flexible } \\
\text { Slightly flexible } \\
\text { Inflexible }\end{array}$ & $\begin{array}{r}1 \\
0.5 \\
0 \\
-0.5\end{array}$ \\
\hline 8 & Customer's Requirement & $\begin{array}{l}\text { Unreasonable requirement that cannot be } \\
\text { honored } \\
\text { Unreasonable requirement that can be } \\
\text { honored } \\
\text { Reasonable requirement }\end{array}$ & $\begin{array}{r}1 \\
0.5 \\
-0.5\end{array}$ \\
\hline 9 & Extension Volume & $\begin{array}{l}\text { More than } 50 \% \text { of standard functionality } \\
\text { Approximately } 30 \% \\
\text { Approximately } 10 \%\end{array}$ & $\begin{array}{r}1 \\
0.6 \\
0.2\end{array}$ \\
\hline 10 & Clear R\&R Definition & $\begin{array}{l}\text { Very clearly defined } \\
\text { Somewhat clearly defined } \\
\text { Unclear }\end{array}$ & $\begin{array}{r}1 \\
0.5 \\
0\end{array}$ \\
\hline 11 & Customer Relationship & $\begin{array}{l}\text { Excellent } \\
\text { Good } \\
\text { Average } \\
\text { Unsatisfactory } \\
\text { Very unsatisfactory }\end{array}$ & $\begin{array}{r}1 \\
0.6 \\
0.2 \\
-0.6 \\
-1\end{array}$ \\
\hline 12 & Project Risk & $\begin{array}{l}\text { Green } \\
\text { Yellow } \\
\text { Red }\end{array}$ & $\begin{array}{c}\text { Risk }<=0.2 \\
0.2<=\text { Risk }< \\
0.4 \\
0.4<=\text { Risk }\end{array}$ \\
\hline 13 & Contingency & $\begin{array}{l}\mathrm{N} / \mathrm{A} \text { due to mediation attributes between } \\
\text { input attribute and result }\end{array}$ & $\mathrm{N} / \mathrm{A}$ \\
\hline 14 & Solution Mapping Ratio & $\begin{array}{l}\text { Approximately } 80 \% \\
\text { Approximately } 60 \% \\
\text { Approximately } 40 \% \\
\text { Less than } 30 \%\end{array}$ & $\begin{array}{l}1 \\
0.7 \\
0.4 \\
0.1 \\
\end{array}$ \\
\hline 15 & $\begin{array}{l}\text { Customer Project } \\
\text { Experience }\end{array}$ & $\begin{array}{l}\text { Experience with a similar-sized project } \\
\text { Experience with a smaller project } \\
\text { No experience }\end{array}$ & $\begin{array}{r}1 \\
0.5 \\
0\end{array}$ \\
\hline
\end{tabular}




\begin{tabular}{|c|c|c|c|}
\hline 16 & Contractual Risk & $\begin{array}{l}\text { Very high } \\
\text { High } \\
\text { Medium } \\
\text { Low } \\
\text { Very Low }\end{array}$ & $\begin{array}{r}1 \\
0.5 \\
0 \\
-0.5 \\
-1\end{array}$ \\
\hline 17 & Profit & $\begin{array}{l}\mathrm{N} / \mathrm{A} \text { due to mediation attributes between } \\
\text { input attribute and result }\end{array}$ & $\mathrm{N} / \mathrm{A}$ \\
\hline 18 & Financial Risk & $\begin{array}{l}\text { Collection risk } \\
\text { Rev Rec issue } \\
\text { No problems anticipated }\end{array}$ & $\begin{array}{r}1 \\
0.7 \\
0\end{array}$ \\
\hline 19 & Project Duration & $\begin{array}{l}\geq 2 \text { years } \\
\text { Approximately } 1 \text { year } \\
\text { Approximately } 6 \text { months } \\
\text { Approximately } 3 \text { months }\end{array}$ & $\begin{array}{l}1 \\
0.7 \\
0.4 \\
0.1\end{array}$ \\
\hline 20 & Contract Type & $\begin{array}{l}\text { T\&M } \\
\text { Fixed price }\end{array}$ & $\begin{array}{r}1 \\
0.5\end{array}$ \\
\hline 21 & Terms \& Conditions & $\begin{array}{l}\text { Agrees with our policies } \\
\text { Do not agree with our policies, but we have } \\
\text { experience with such a case } \\
\text { Critical items do not agree with our policies }\end{array}$ & $\begin{array}{r}1 \\
-0.5 \\
-1\end{array}$ \\
\hline 22 & Bidding Margin & $\begin{array}{l}\text { Greater than } 40 \% \\
\text { Approximately } 30 \% \\
\text { Approximately } 20 \% \\
\text { Approximately } 10 \% \\
\text { Less than } 10 \%\end{array}$ & $\begin{array}{r}1 \\
0.7 \\
0.4 \\
0.1 \\
0\end{array}$ \\
\hline 23 & Competition in Bidding & $\begin{array}{l}\text { High } \\
\text { Medium } \\
\text { Negligible }\end{array}$ & $\begin{array}{r}1 \\
0.5 \\
0\end{array}$ \\
\hline 24 & Reference & $\begin{array}{l}\text { Reference exists in the same industry } \\
\text { Reference exists in another industry } \\
\text { No known reference }\end{array}$ & $\begin{array}{r}1 \\
0.5 \\
0\end{array}$ \\
\hline
\end{tabular}

Table 2. Fuzzy values for concept nodes 


\begin{tabular}{|c|c|c|c|c|c|c|c|c|c|c|c|c|c|c|c|c|c|c|c|c|c|c|c|c|}
\hline & 1 & 2 & 3 & 4 & 5 & 6 & 7 & 8 & 9 & 10 & 11 & 13 & 14 & 15 & 16 & 17 & 18 & 19 & 20 & 21 & 22 & 23 & 24 & 12 \\
\hline \& & 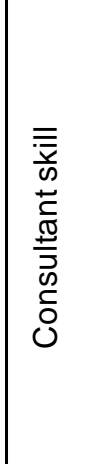 & 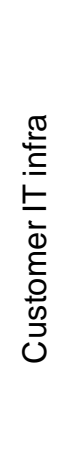 & 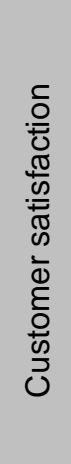 & 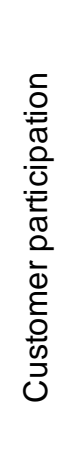 & 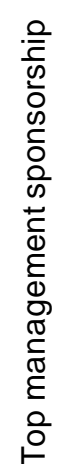 & 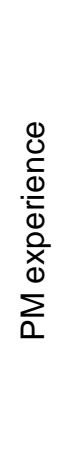 & 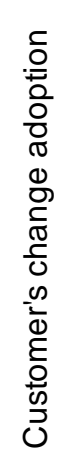 & 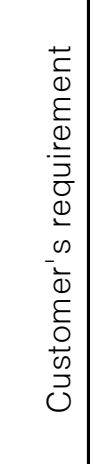 & 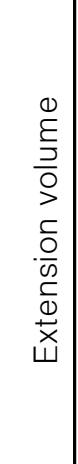 & 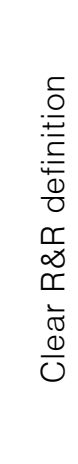 & 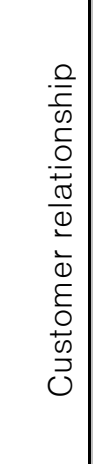 & 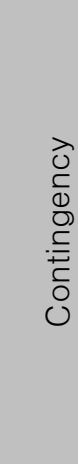 & 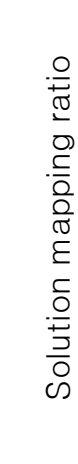 & 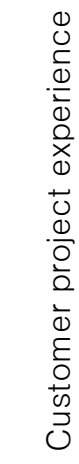 & 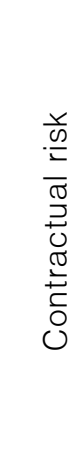 & $\begin{array}{l}\text { 풍 } \\
\stackrel{0}{0} \\
\text { L }\end{array}$ & 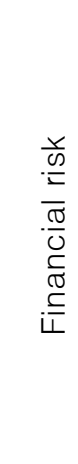 & 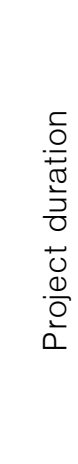 & 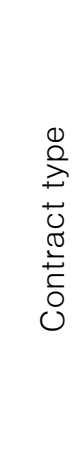 & $\begin{array}{l}\stackrel{\infty}{\not} \\
\vdash\end{array}$ & 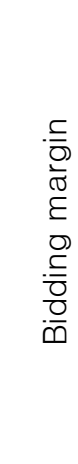 & 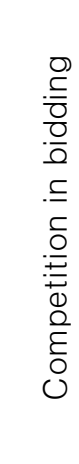 & 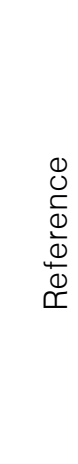 & 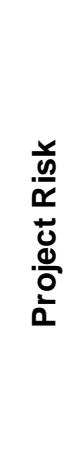 \\
\hline 1 & 1.0 & & & & 1.0 & & 1.0 & 0.5 & 0.6 & 1.0 & 1.0 & & 1.0 & 1.0 & -1.0 & 0. & 0.0 & 0. & 1.0 & 1.0 & 0. & 0.0 & 0.5 & 0 \\
\hline 2 & 0.5 & .0 & 0.0 & -1.0 & 0.0 & .7 & -0.5 & 1.0 & 1.0 & 0.5 & 0.0 & 0.0 & 0.6 & 1.0 & 0.5 & 0.0 & 0.0 & 0.7 & 0.5 & -0.5 & 0.4 & 1.0 & 0.0 & 0.52 \\
\hline 3 & 0.7 & & 0.0 & -0.5 & 0.7 & 0.5 & -0.2 & 1.0 & 0.6 & 0.5 & 0.0 & 0.0 & 0.7 & 0.5 & 0.0 & 0.0 & 0.0 & 0.7 & 0.5 & -0.5 & 0.4 & 0.2 & .0 & 0.34 \\
\hline 4 & 0.3 & & 0.0 & -1.0 & 0. & 0 & 0.0 & 0 & 0.6 & 0 & 0.0 & & 0. & & 0.0 & 0. & & & 0.5 & -0. & & 1.0 & & 0.73 \\
\hline 5 & 0.5 & & 0.0 & -1.0 & 0.0 & 0. & -0.2 & 1.0 & 1.0 & 0 & 0.0 & & 0.5 & & 0.5 & 0. & & & 0.5 & -1.0 & 1.0 & 1.0 & 0 & 1.04 \\
\hline 6 & 0.5 & 1. & $\overline{0.0}$ & 0.7 & 1.0 & 0.7 & 0.7 & 0.5 & 0.6 & 1. & 1.0 & 0.0 & 1.0 & 1.0 & -0.5 & 0.0 & 0.0 & 0.7 & 0.5 & 1.0 & 0.4 & 0.7 & 1.0 & 0.52 \\
\hline 7 & 1.0 & & 0. & 0. & 1. & 1. & 0.8 & 5 & 0.2 & 1 & 1. & 0 & 1. & 1. & -1.0 & 0.0 & 0. & 0 & 1.0 & 1.0 & .4 & 0.2 & & 0.2 \\
\hline 8 & 0.7 & 0.8 & 0.0 & 0.5 & 0.0 & 0.7 & 0.0 & -0.5 & 0.6 & 1.0 & 0.0 & 0.0 & 0.8 & 0.5 & -0.5 & 0.0 & 0.0 & 0.6 & 0.5 & 1.0 & 0.4 & 0.7 & .0 & 0.36 \\
\hline 9 & 0.7 & 0.8 & 0.0 & 0.2 & 0.5 & 0.7 & -0.2 & 1.0 & 1.0 & 0.4 & -0.2 & 0.0 & 0.5 & 1.0 & 1.0 & 0.0 & 0.7 & 0.7 & 0.5 & -0.5 & 0.4 & 1.0 & 0.0 & 0.68 \\
\hline 10 & 0.5 & 1.0 & 0.0 & 1.0 & 1.0 & 1.0 & 1.0 & -0.5 & 0.2 & 1.0 & 1.0 & 0.0 & 1.0 & 1.0 & -1.0 & 0.0 & 0.0 & 0.7 & 1.0 & 1.0 & 0.4 & 0.5 & 1.0 & 0.22 \\
\hline
\end{tabular}

Table 3. Training Data 


\begin{tabular}{|c|c|c|c|c|}
\hline Time Node & A & B & C & D \\
\hline 0 & 0.5 & 0.6 & $\mathrm{~F}\left(0.6^{*} 0.3\right)$ & $\mathrm{N} / \mathrm{A}$ \\
\hline 1 & 0.5 & 0.6 & $\mathrm{C}_{0}=\mathrm{f}\left(0.5^{\star} 0.8\right)$ & $\mathrm{D}_{0}+\mathrm{f}\left(0.5^{\star}(0.2 \sim 0.8)+\left(\mathrm{C}_{0}\right)^{\star} 0.6\right)$ \\
\hline 2 & 0.5 & 0.6 & $\mathrm{C}_{0}+\mathrm{f}\left(0.5^{\star} 0.8\right)$ & $\mathrm{D}_{1}+\mathrm{f}\left(\left(\mathrm{C}_{1}\right)^{\star} 0.6\right)$ \\
\hline
\end{tabular}

Table 4 Node value changes in different time period in the agent based inference of the example FCM ( $f()$ : inference function) 


\begin{tabular}{|c|c|c|c|c|c|c|c|c|c|c|c|c|c|c|c|c|c|c|c|c|c|c|c|}
\hline & 1 & 2 & 4 & 5 & 6 & 7 & 8 & 9 & 10 & 11 & 14 & 15 & 16 & 18 & 19 & 20 & 21 & 22 & 23 & 24 & & & \\
\hline \# & 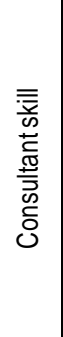 & 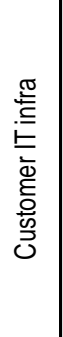 & 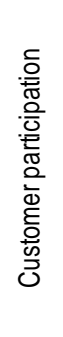 & 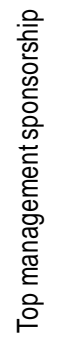 & 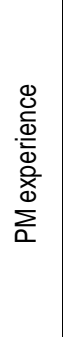 & 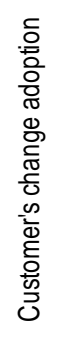 & 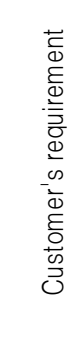 & 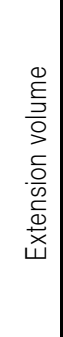 & 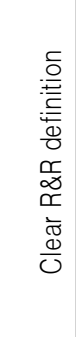 & 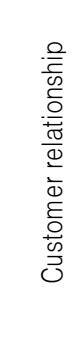 & 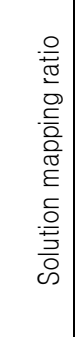 & 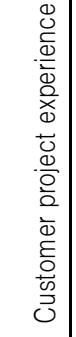 & 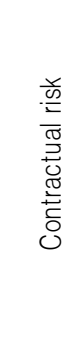 & 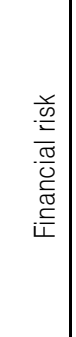 & 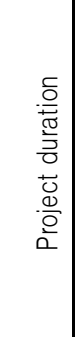 & 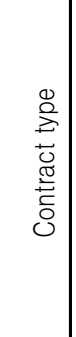 & $\begin{array}{l}\underset{\infty}{ } \\
\vdash\end{array}$ & 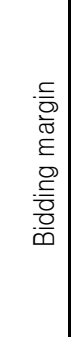 & 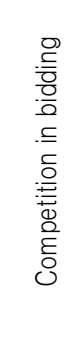 & 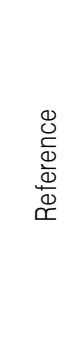 & $\begin{array}{l}\frac{0}{\mathcal{N}} \\
\stackrel{N}{N} \\
\vec{N} \\
\stackrel{N}{1}\end{array}$ & 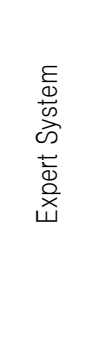 & 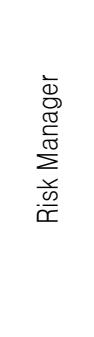 \\
\hline 1 & 1.0 & 1.0 & 1.0 & 1.0 & 1.0 & 1.0 & 0.5 & 0.6 & 1.0 & 1.0 & 1.0 & 1.0 & $\begin{array}{l}-1.0 \\
\end{array}$ & 0.0 & 0.5 & 1.0 & 1.0 & 0.7 & 0.0 & 1.0 & -1.00 & Green & Green \\
\hline 2 & 0.5 & 1.0 & -1.0 & 0.0 & 0.7 & -0.5 & 1.0 & 1.0 & 0.5 & 0.0 & 0.6 & 1.0 & 0.5 & 0.0 & 0.7 & 0.5 & -0.5 & 0.4 & 1.0 & 0.0 & -0.72 & Yellow & Yellow \\
\hline 3 & 0.7 & 0.5 & -0.5 & 0.7 & 0.5 & -0.2 & 1.0 & 0.6 & 0.5 & 0.0 & 0.7 & 0.5 & 0.0 & 0.0 & 0.7 & 0.5 & -0.5 & 0.4 & 0.2 & 1.0 & -0.99 & Green & Yellow \\
\hline 4 & 0.3 & 0.5 & -1.0 & 0.0 & 0.7 & 0.0 & 0.5 & 0.6 & 0.5 & 0.0 & 0.6 & 0.5 & 0.0 & 0.0 & 0.5 & 0.5 & -0.5 & 0.1 & 1.0 & 0.0 & -0.71 & Yellow & Yellow \\
\hline 5 & 0.5 & 0.7 & -1.0 & 0.0 & 0.7 & -0.2 & 1.0 & 1.0 & 0.5 & 0.0 & 0.5 & 0.5 & 0.5 & 0.0 & 0.7 & 0.5 & $\begin{array}{l}-1.0 \\
\end{array}$ & 0.0 & 1.0 & 0.0 & 0.03 & Red & Red \\
\hline 6 & 0.5 & 1.0 & 0.7 & 1.0 & 0.7 & 0.7 & 0.5 & 0.6 & 1.0 & 1.0 & 1.0 & 1.0 & -0.5 & 0.0 & 0.7 & 0.5 & 1.0 & 0.4 & 0.7 & 1.0 & -0.99 & Green & Green \\
\hline 7 & 1.0 & 0.7 & 0.7 & 1.0 & 1.0 & 0.8 & -0.5 & 0.2 & 1.0 & 1.0 & 1.0 & 1.0 & -1.0 & 0.0 & 0.6 & 1.0 & 1.0 & 0.4 & 0.2 & 1.0 & -1.00 & Green & Green \\
\hline 8 & 0.7 & 0.8 & 0.5 & 0.0 & 0.7 & 0.0 & -0.5 & 0.6 & 1.0 & 0.0 & 0.8 & 0.5 & -0.5 & 0.0 & 0.6 & 0.5 & 1.0 & 0.4 & 0.7 & 1.0 & -0.99 & Green & Green \\
\hline 9 & 0.7 & 0.8 & 0.2 & 0.5 & 0.7 & -0.2 & 1.0 & 1.0 & 0.4 & -0.2 & 0.5 & 1.0 & 1.0 & 0.7 & 0.7 & 0.5 & -0.5 & 0.4 & 1.0 & 0.0 & -0.17 & Yellow & Yellow \\
\hline 10 & 0.5 & 1.0 & 1.0 & 1.0 & 1.0 & 1.0 & -0.5 & 0.2 & 1.0 & 1.0 & 1.0 & 1.0 & -1.0 & 0.0 & 0.7 & 1.0 & 1.0 & 0.4 & 0.5 & 1.0 & -0.99 & Green & Green \\
\hline 11 & 0.7 & 0.0 & -1.0 & 1.0 & 0.5 & -0.1 & 1.0 & 1.0 & 0.0 & 0.0 & 0.5 & 0.0 & 1.0 & 1.0 & 0.7 & 0.5 & -1.0 & 0.0 & 1.0 & 0.0 & 0.90 & Red & Red \\
\hline 12 & 0.7 & 1.0 & 1.0 & 1.0 & 1.0 & 1.0 & 0.5 & 0.2 & 1.0 & 1.0 & 0.6 & 1.0 & 0.5 & 0.0 & 0.6 & 1.0 & 1.0 & 0.4 & 0.0 & 1.0 & -1.00 & Green & Green \\
\hline 13 & 0.6 & 0.5 & -0.5 & 0.5 & 0.7 & -0.5 & 1.0 & 1.0 & 0.0 & 0.0 & 0.5 & 0.5 & 1.0 & 0.0 & 0.7 & 0.5 & -0.5 & 0.0 & 1.0 & 0.0 & -0.11 & Yellow & Red \\
\hline 14 & 0.7 & 1.0 & 1.0 & 1.0 & 1.0 & 1.0 & 0.5 & 0.6 & 1.0 & 1.0 & 0.6 & 1.0 & -1.0 & 0.0 & 0.7 & 1.0 & 1.0 & 0.7 & 0.2 & 1.0 & -1.00 & Green & Green \\
\hline 15 & 0.6 & 0.0 & -1.0 & 0.7 & 0.7 & -0.5 & 1.0 & 0.6 & 0.2 & 0.0 & 0.7 & 0.0 & 0.5 & 0.7 & 0.7 & 0.5 & -0.5 & 0.0 & 1.0 & 0.0 & 0.10 & Red & Red \\
\hline 16 & 0.7 & 0.5 & 1.0 & 1.0 & 1.0 & 0.5 & -0.5 & 0.2 & 0.9 & 0.0 & 0.8 & 0.5 & -0.5 & 0.0 & 0.7 & 0.5 & 1.0 & 0.4 & 0.6 & 1.0 & -0.99 & Green & Green \\
\hline 17 & 0.6 & 0.7 & 1.0 & 0.0 & 0.5 & 0.5 & -0.5 & 0.0 & 1.0 & 0.0 & 1.0 & 1.0 & -1.0 & 0.0 & 0.3 & 1.0 & 1.0 & 0.7 & 0.0 & 1.0 & -1.00 & Green & Green \\
\hline 18 & 0.5 & 0.8 & 0.7 & 1.0 & 0.7 & 1.0 & -0.5 & 0.2 & 1.0 & 1.0 & 0.8 & 1.0 & -1.0 & 0.0 & 0.7 & 1.0 & 1.0 & 0.4 & 0.0 & 1.0 & -1.00 & Green & Green \\
\hline 19 & 0.5 & 0.8 & 0.7 & 0.8 & 0.5 & 0.7 & -0.5 & 0.0 & 1.0 & 1.0 & 1.0 & 1.0 & -1.0 & 0.0 & 0.5 & 1.0 & 1.0 & 0.4 & 0.6 & 0.0 & -0.99 & Green & Green \\
\hline 20 & 0.6 & 1.0 & $\begin{array}{l}-1.0 \\
\end{array}$ & 7.0 & 0.7 & $\begin{array}{l}-1.0 \\
\end{array}$ & 1.0 & 1.0 & 0.0 & 0.0 & 0.6 & 1.0 & 1.0 & 0.7 & 0.7 & 0.5 & $\begin{array}{l}-1.0 \\
\end{array}$ & 0.0 & 1.0 & 0.0 & 0.65 & Red & Red \\
\hline 21 & 0.6 & 0.8 & 0.7 & 0.9 & 1.0 & 0.0 & 0.5 & 0.6 & 0.5 & 0.0 & 0.8 & 0.5 & -0.5 & 0.0 & 0.7 & 0.5 & 1.0 & 0.1 & 1.0 & 0.0 & -0.97 & Green & Green \\
\hline 22 & 0.6 & 0.0 & 0.0 & 0.5 & 0.7 & 0.0 & 1.0 & 0.2 & 0.5 & 0.0 & 0.7 & 0.5 & 0.0 & 0.0 & 0.6 & 0.5 & 1.0 & 0.4 & 0.6 & 1.0 & -0.98 & Green & Green \\
\hline 23 & 0.6 & 0.5 & 0.0 & 0.0 & 0.7 & -0.2 & 1.0 & 1.0 & 0.5 & 0.0 & 0.4 & 0.5 & 0.0 & 0.0 & 0.7 & 1.0 & 1.0 & 0.4 & 0.6 & 0.0 & -0.97 & Green & Green \\
\hline 24 & 0.7 & 0.7 & 0.5 & 0.7 & 0.8 & 0.3 & 0.5 & 0.4 & 0.5 & 0.0 & 0.7 & 0.5 & 0.0 & 0.0 & 0.7 & 0.5 & 1.0 & 0.4 & 0.7 & 0.0 & -0.99 & Green & Green \\
\hline 25 & 0.7 & 1.0 & 1.0 & 1.0 & 0.9 & 1.0 & -0.5 & 0.0 & 1.0 & 1.0 & 1.0 & 1.0 & -1.0 & 0.0 & 0.7 & 1.0 & 1.0 & 0.7 & 0.0 & 1.0 & -1.00 & Green & Green \\
\hline 26 & 0.7 & 1.0 & 1.0 & 1.0 & 0.7 & 1.0 & -0.5 & 0.2 & 1.0 & 1.0 & 0.9 & 1.0 & -0.5 & 0.0 & 0.7 & 1.0 & 1.0 & 0.7 & 0.7 & 1.0 & -0.99 & Green & Green \\
\hline 27 & 0.6 & 0.5 & 0.5 & 0.7 & 1.0 & -0.2 & 0.5 & 1.0 & 1.0 & 1.0 & 0.6 & 0.5 & 0.5 & 0.0 & 1.0 & 0.5 & 1.0 & 0.1 & 0.5 & 0.0 & -0.99 & Green & Green \\
\hline 28 & 0.7 & 0.7 & 0.5 & 0.7 & 0.8 & 0.3 & 0.5 & 0.4 & 0.5 & 0.0 & 0.7 & 0.5 & 0.0 & 0.0 & 0.7 & 0.5 & 1.0 & 0.4 & 0.7 & 1.0 & -0.99 & Green & Green \\
\hline 29 & 0.6 & 0.0 & -0.2 & 0.5 & 0.7 & 0.0 & 1.0 & 0.2 & 0.5 & 0.0 & 0.7 & 0.5 & 0.0 & 0.0 & 0.7 & 0.5 & 1.0 & 0.1 & 0.7 & 1.0 & -0.96 & Green & Green \\
\hline 30 & 0.7 & 0.6 & 0.0 & 0.3 & 0.8 & 0.3 & 0.5 & 0.4 & 0.5 & 0.0 & 0.8 & 0.5 & 0.5 & 0.0 & 0.6 & 0.5 & -0.5 & 0.4 & 0.6 & 1.0 & -0.99 & Green & Green \\
\hline 31 & 0.7 & 0.7 & 0.0 & 0.7 & 0.8 & 0.0 & 1.0 & 0.6 & 0.5 & -0.5 & 0.6 & 1.0 & 0.5 & 0.7 & 0.7 & 0.5 & 1.0 & 0.1 & 1.0 & 0.0 & -0.44 & Yellow & Yellow \\
\hline 32 & 0.6 & 1.0 & 0.0 & 0.0 & 0.8 & 0.0 & 0.5 & 0.4 & 1.0 & -0.5 & 0.7 & 1.0 & 1.0 & 0.0 & 0.4 & 0.5 & 1.0 & 0.1 & 0.7 & 1.0 & $\mid-0.90$ & Green & Green \\
\hline
\end{tabular}

Table 5. Validation test results 
